\title{
Participatory Assessment Model (PAM) for the Sustainability of Rural Livelihoods Based on Climate Change
}

\author{
Khademibami Leyla and Pazouki Pejman
}

\begin{abstract}
The current study is an attempt to provide a tool that can be used to manage sustainable rural livelihoods more effectively. This tool also avoids the harm of resources wastage as much as possible. The indicators of the sustainability of livelihood are investigated in this paper by reviewing the past and recent studies. According to the literature reviews of sustainable development, the sustainability of livelihood can be included in the main categories of rural assets. Therefore, based on the seven years fieldwork experience of this paper's authors in working with local rural communities and interviews with specialists through a snowball method the Participatory Rural Appraisal method is identified as the best way for the extraction of indicators. As a result of the investigations in this paper, the participatory assessment model (PAM) is proposed by using design thinking techniques. The possibility of converting qualitative values into quantitative ones is provided by drawing of hypothetical positions and mathematical formulas. This model attempts are made to achieve livelihood sustainability as a perspective. Additionally, development projects aimed at conservation in the face of climate change can use this model to assess their own perspective. Using PAM can also help practitioners in this area to make more realistic planning.
\end{abstract}

Index Terms-Climate change, conservation, indicators, participatory assessment model, sustainable rural livelihood.

\section{INTRODUCTION}

In the $21^{\text {st }}$ century, sustainable rural livelihoods will be necessary for many more people [1]. The concept of assessing the sustainability of rural livelihood has a key role in sustainable development. A vital tool for achieving the sustainable development goals proven by Agenda 21, is Indicators [2]. SL approaches require on-going learning throughout implementation and therefore highlight the importance of monitoring and evaluation (M\&E) [3]. Agricultural intensification, livelihood diversification, and migration are different livelihood strategies [4]. Also, "Sustainable livelihoods have many dimensions and multiple causalities. They take different forms for different people in a different environment" [5]. How to measure livelihoods despite these diverse dimensions and in different environments?

Manuscript received September 23, 2019; revised February 23, 2020 This work was supported in part by Ms. Mitra Ataei and Mr. Kasra Miremadi.

Leyla Khademibami is with the Iranian Culture and Sustainable Development Institute, 80305, Iran (e-mail: leylakhademi@gmail.com).

Pejman Pazouki was with Tehran University, Tehran (e-mail: pejman.pazouki@ut.ac.ir).
This paper stems from the 7 years of writers' experiences in the field of sustainable livelihoods, through which we have realized the need for a simple model for an assessment of participatory sustainability of existing livelihoods, a pre-assessment of the sustainability of those livelihoods that can be revived, or a pre-assessment of the creation of complementary and new livelihoods. It tries to provide a model that can measure the state of livelihood and its distance with sustainability. And seeks to answer the question: How can sustainability indicators be evaluated in relation to the different sources and unique conditions of each village and the different livelihood strategies?

Experience has shown that some livelihoods have failed, in spite of initial predictions, and after preparation of economic costs and human resources to launch or revive. Or it is true that, for example, they have solved an economic problem, but on the other hand they have raised a carbon footprint. This model, as a reviewer, can help planners make better decisions.

\section{Methodology}

Through the current paper, the indicators of the sustainability of livelihood are studied by reviewing the literature of sustainable development, and it was concluded that they can be included in the main categories of rural assets. Based on the seven years of authors' fieldwork experience in working with local rural communities on the one hand, and on the other hand, collaboration with specialists through a snowball method, the PRA method is identified as the best way for the extraction of indicators. Then, the participatory assessment model (PAM) is proposed, using design thinking techniques. And the possibility of converting qualitative values into quantitative ones is provided by drawing of hypothetical positions and mathematical formulas. The concluded results are depicted in the graph with the help of the numbers, and it will show a picture of the situation.

\section{A HiSTORY OF INDICATORS \& ASSESSMENTS IN SUSTAINABILITY}

Many different forms of sustainability assessment have emerged across the world in about two decades [6]. In each framework, there is a need for an indicator and a tool for evaluation and measurement to ensure progress.

Tunstall (1992, 1994), Gallopín (1997), Chen et al. (2016), and Ford et al., (2013), have discussed important and major functions for using indicators for the assessment and 
evaluation of conditions, movements in relation to goals and targets, changes, the effectiveness of adaptation activities; for identification and comparing situations, vulnerabilities, gaps in resilience; for definition of targeted policies; and for anticipation of future circumstances and movements [7], [8]. Similar reasons exist for the importance of using indicators for measuring sustainable livelihoods. And experts also agree that using sustainability indicators for assessment, provided that they are selected and applied carefully and appropriately [9].

To evaluate, there are different models and methodologies available. Here are some of them that were consistent with sustainable development.

\begin{tabular}{|c|c|c|c|}
\hline Year & Names of method or tool & Abb. & For What? \\
\hline 1996 & $\begin{array}{l}\text { Participatory } \\
\text { Environmental Valuation } \\
\text { a }\end{array}$ & - & $\begin{array}{l}\text { Environmental } \\
\text { valuation }\end{array}$ \\
\hline 1998 & Necessities & BNS & Measuring poverty \\
\hline 1999 & $\begin{array}{l}\text { Household Livelihood } \\
\text { Security Assessment }\end{array}$ & HLS & $\begin{array}{l}\text { Household Livelihood } \\
\text { Security }\end{array}$ \\
\hline 2002 & $\begin{array}{l}\text { Participatory monitoring } \\
\text { and evaluation }^{\mathrm{d}}\end{array}$ & PM\&E & $\begin{array}{l}\text { Biodiversity } \\
\text { assessment }\end{array}$ \\
\hline 2003 & Coping Strategies Index ${ }^{\mathrm{e}}$ & CSI & Food security \\
\hline 2006 & $\begin{array}{l}\text { Sustainability Assessment } \\
\text { Model }^{\mathrm{f}}\end{array}$ & SAM & $\begin{array}{l}\text { Project } \quad \text { evaluation } \\
\text { processes }\end{array}$ \\
\hline 2008 & $\begin{array}{l}\text { Committee on } \\
\text { Sustainability Assessment } \\
\mathrm{g}\end{array}$ & $\cos ^{1}$ & $\begin{array}{l}\text { Sustainability } \\
\text { agriculture }\end{array}$ \\
\hline 2010 & $\begin{array}{l}\text { Sustainable Infrastructure } \\
\text { Land-use Environment } \\
\text { and Transport Model }^{\mathrm{h}}\end{array}$ & $\begin{array}{c}\text { SILEN } \\
\mathrm{T}\end{array}$ & Sustainability \\
\hline 2013 & $\begin{array}{l}\text { Sustainability Assessment } \\
\text { Tool }^{\text {i }}\end{array}$ & SAT & $\begin{array}{l}\text { Links between } \\
\text { gender-sensitive } \\
\text { approaches \& } \\
\text { sustainability }\end{array}$ \\
\hline
\end{tabular}

Examined models in table I, some of which are simple and some are complex, are based on the objectives of sustainable development for evaluation. Among them, it seems that the HLS, COSA, can be partly used to assess the sustainability of livelihoods.

\section{PARTicipatory Assessment MOdel (PAM):}

This model provides an opportunity to evaluate the sustainability of livelihood in a collaborative way and at different levels of individual, family and group. Also, using this model, it can be estimated that the livelihood that is to be restored or created, is how much close to sustainability. More importantly, it provides a picture of the status quo and a favorable situation that can be helpful in planning and achieving sustainability.

In addition, the position of an indicator and the extent to which it can be achieved in the short or long term is possible. With the help of it, it can be predicted to some extent that the

\footnotetext{
${ }^{1} \operatorname{COSA}$ is a global consortium of partners dedicated to accelerating agricultural sustainability through robust monitoring and evaluation.
}

creation or continuation of an activity how is contributed to and effective in the sustainability of the livelihood.

Another important point that this model has tried to consider is the LCDDU characteristics of the village. This term was first introduced by Chambers in his famous book WHOSE REALITY COUNTS?, he stated that: "For the local, complex, diverse, dynamic and uncontrolled (LCDDU) reality of the poor to count more, and to support sustainable rural livelihoods requires new policies, research, and methods.

To differentiate local conditions, histories, and trajectories, (b) to enable local people to conduct more of the analysis themselves, and (c) to achieve radical professional change [1]."

Given this dynamism, diversity, and complexity, there is a need for a regular updating of the evaluation, in which this important point is considered in PAM. On the other hand, the sustainability of livelihood depends on all effective factors and aspects [19].

To understand these factors, it's best to go over the famous definition of sustainable livelihood by Chambers \& Conway, (1992) which says: "A livelihood comprises the capabilities, assets (including both material and social resources) and activities required for a means of living. A livelihood is sustainable when it can cope with and recover from stresses and shocks, maintain or enhance its capabilities and assets, while not undermining the natural resource base" [5].

According to this definition, "sustainability occurs when it maintains or enhances its capabilities and assets" (Ibid). Based on The SL Framework, these assets include Human, Natural, Social, Financial, and Physical. In a comprehensive study conducted by Nowruzi and Hayati in one of the provinces of Iran, it is concluded that: "Five categories of human, social, economic, physical and environmental factors are related to the sustainability of livelihoods from the perspective of farmers [20]".

This model is defined by considering five capital based on the SD table to achieve sustainability. Chambers said that "to decide to empower local people to conduct more appraisal, analysis and planning themselves, and to set up procedures and institutions to fit in with their disparate demands [1]". The indicators of PAM will be extracted in a division of five capital through the Participatory Rural Appraisal (PRA) method and by local people. It is important to use the participatory approach to extract indicators to achieve the sustainability of livelihoods. Looking at the eyes of the main owners of livelihoods helps more realistic and efficient indicators to be more tangible and prioritized. PRA proper, which is empowering, enabling local people to take over and carry through the processes of appraisal, analysis, and action themselves, and to own the outcomes [1].

On the other hand, taking into account the five capital raised in SD helps to measure all aspects of sustainability together and developing a resource does not harm the other resource or resources. Attempting to present this model is worth considering. In planning for sustainable rural livelihood strategies, one of the areas to be considered is the role of actors in that area.

Due to the importance and impact of actors on the indicators, in PAM, the relationship between the indicators of 
sustainability with the actors, which can be extracted in a PRA method, can be determined.

\section{HOW DOES THIS MODEL WORK?}

Indicators are developed using a participatory approach like the PRA. In this way, the target group is invited to take FGD sessions. The target group can be a person, family, or village group. With relative cognitive methods, the status quo is achieved. Before public meetings with direct observation methods, interviews with local people, studying documents and previous reports, and walking and talking with people, preliminary information has been obtained.

Then, in the meetings, the status of the various types of capital is measured, for example, five assets ${ }^{2}$, Human, Natural, Social, Financial and Physical. Sustainability of livelihoods is considered as the basis, and people describe the current status of their assets.

Next specifying the indicators in each asset, the method of pair comparison technique should determine the weight or value of each asset separately. After this weighting, it is obligatory to determine the status of each indicator. In this model, three conditions are considered for each indicator:

Condition 1: Affiliation or "cannot have unless..."

This means that it cannot have irrigation technology unless the electricity is connected to the village. Having new technology is dependent on the electricity that is not currently in the village.

Condition 2: Possible condition or "likely to be" because there is infrastructure.

This means that it can have a road, for example, because the main road is drawn and only needs to be submerged and paved, so it is possible and more accessible to reach.

Condition 3: certain condition or "already have"

This means that the indicator is currently available, for example, the family has enough money to set up a pottery workshop.

According to these definitions, one of these three situations is assigned to each indicator in the following diagram, with consideration of the weights previously given in the paired comparison method. We assume that this graph is estimated for economic indicators at the local group level. Which we showed them with $\mathrm{z}$, and we determined their weights and their position based on three states in the graph. This diagram is provided to give an example and a better understanding and is not based on reality.

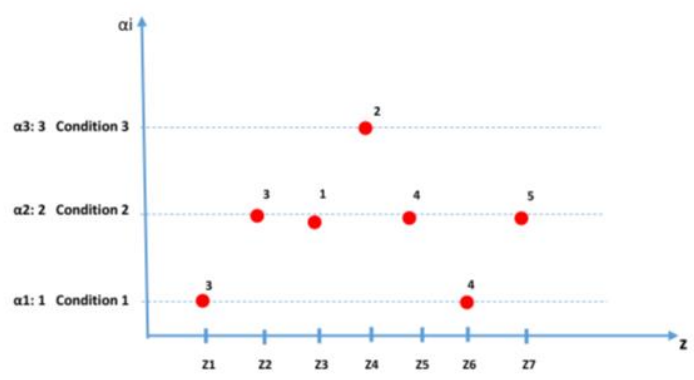

Fig. 1. An example of indicators, their weight, and position in one of three hypothetical states.
In diagram 1, the $\mathrm{z}$-axis shows the indicators and $\alpha \mathrm{i}$ axis shows the situations from 1 to 3 . The marked points indicate the position of each indicator in one of the three states, with the weight of each one registered alongside it.

With these specifications, we assume that $\alpha \mathrm{i}$ are for $\mathrm{i}:\{1 \ldots$ $\mathrm{n}\}$, where $\mathrm{n}: 1$ or 2 or 3 denotes the positions and $\mathrm{zj}$ for $\mathrm{j}:\{1 \ldots$ $\mathrm{m}\}$, where $\mathrm{m}$ is the number of indicators, but these indicators have different meanings, showing their coefficients with $\alpha \mathrm{j}$. The average is calculated as follows.

Consequently, with the following formula, it is possible to obtain the mean of assets:

$$
\overline{\mathrm{A}}=\frac{\sum_{j=1}^{m} \alpha_{j} A_{j}}{\sum_{j=1}^{m} \alpha_{j}}
$$

These results can also be presented in the following diagram for each sub-category, for example, the economic asset can be considered in the image below, or as an average using the (1), for example, in economic assets.

We obtained the following schematic image in the method of design thinking, through which it is able to schematically show evaluation and to study the position of the evaluation indicators in various situations, for example, the initial position or status, and the establishment of the desired status and paths to reach it.

The average calculation is appropriate for the time that we want to have a general view of the status of each of the five capital markets. Otherwise, for each asset, a chart can be given and for each indicator, there is a separate line.

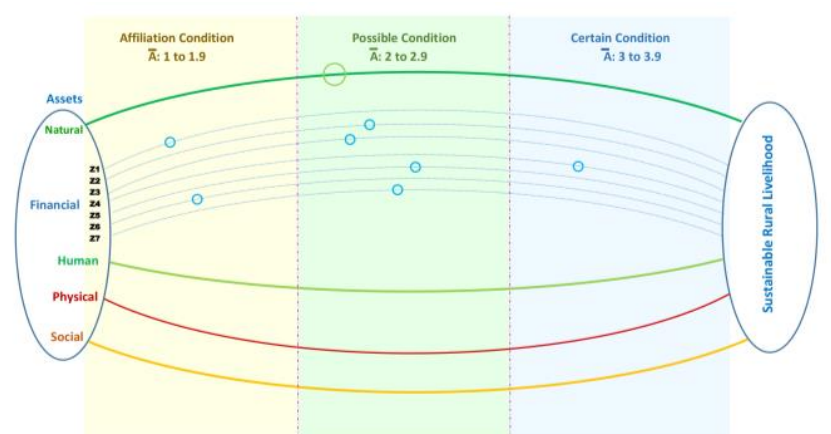

Fig. 2. The stage of depicting the status of the indicators and showing their position within their distance from sustainability.

This chart, if drawn up in the initial assessment at the initial stage of the work, can help to determine which indicators of each asset needs to be improved in order to achieve sustainability, or to determine its infrastructure and related conditions.

Also in this chart, the indicators are both presented as an average of one asset and as a form of individual indicators in an asset. In addition, the relationship between indicators and their impact on each other can also be identified. It makes a possibility to predict the impact of each indicator on the progress or regress of other indicators. This means that for the development of one capital, the other capital should not be harmed.

\footnotetext{
${ }^{2}$ Based on The SL Framework.
} 
For example, by pursuing economic development in an area, ecotourism wants to develop. Naturally, there will be changes in the physical or infrastructure sectors. At the same time, its positive and negative effects on the environment, human and social, must also be measured. The livelihood will be sustainable when the development of each of these funds has a positive effect on the other.

If drawn in the final assessment, it shows what indicators have improved and, on the contrary, maybe hurt. Another part that the charts can help with is the role of each actor that can contribute to the improvement and stability of the indicators. Of course, the list of actors will be extracted in a collaborative way. Here are some examples of actors and their relationship with the indexes.

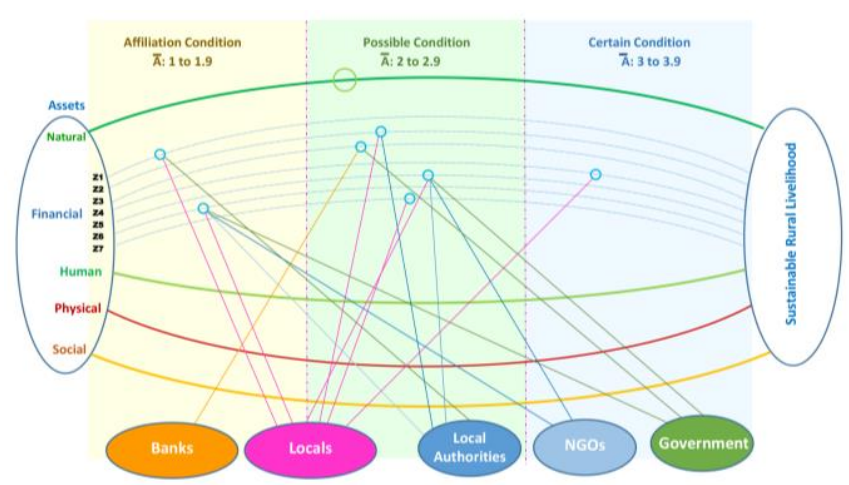

Fig. 3. The stage of depicting the status of the indicators and actors who can influence it.

\section{Who CAN USE This Model?}

Facilitators, entrepreneurs, planners, conservation and development project managers, and NGOs can use this model.

Using this model can prevent the cost of uncertain results. Also, it can enable practitioners to sustain the livelihoods of the rural community, which are often worrisome in the sustainability of natural resources then they create livelihoods at a high cost, which may hurt the sustainability of social and human resources.

The methodological challenge is further to develop and spread approaches and methods to enable local people, especially those who are disadvantaged, to conduct their own appraisals, analysis, and planning, to take command of their own resources, and to negotiate with and drawn down on Government, NGOs and other sources of support.

\section{DISCUSSION AND CONCLUSION}

Awareness of the components and influential indicators will contribute to the development and facilitating of sustainable rural livelihoods [21]. More importantly, the evaluation helps prevent additional costs. Because the assessment of the current situation can help to select the appropriate strategy, it can be measured in the next stages of development and approaching the vision of the strategy.

In order to achieve sustainable rural livelihoods, including livelihoods diversification, establishing an appropriate combination of livelihoods in rural areas, reducing livelihoods and adapting the way of working with environmental resilience, there is a need for evaluation.

In addition, one of the shocks brought about by climate change can be economic uncertainty, as is sustainability when a livelihood can resilient shocks and pressures. [5] Resilience can move steadily when all of the assets reach the strength of the resistance in a balanced way.

The tools previously used to measure indices do not include all of the assets simultaneously. It can cause the resistance of the other capital to be destroyed by creating resistance in one capital.

The PAM can provide an opportunity to examine all of these in different situations and regions. Indicators need to have a criterion to determine more precisely. In this model, the criterion of five assets is considered. On the other hand, livelihood assets are well-defined and changeable. When the indicators are identified in a collaborative manner and by their main owners, there will be more confidence if all of its dimensions are considered. Obviously, the perspective must be defined and the indicators should be selected according to their achievement to it.

On the other hand, this model is intended to measure triple status, which helps the facilitator to extract indicator situations in a simpler and more realistic participatory way. This measurement method is not used in evaluation models.

This model helps to assess not only on the basis of economic progress but also on the increased resilience and sustainable use of natural resources and other resources alongside. The weight of the indicators is certainly differed according to location and geography. And one of the most important benefits of this model is the articulation between each of the indicators and actors that can be effective in advancing it.

Experience has shown that some livelihoods have failed, in spite of initial predictions, and after preparation of economic costs and human resources to launch or revive. Or it is true that, for example, they have solved an economic problem, but on the other hand they have raised a carbon footprint. The PAM, as a reviewer, can help planners make better decisions.

\section{CONFLICT OF INTEREST}

The authors declare no conflict of interest.

\section{AUTHOR CONTRIBUTIONS}

Literature review and research were done by both authors. With field research, Mr. Pejman Pazuki provided useful information for designing. The model had designed by Ms. Leyla Khademibami using design thinking. The participatory method was presented to extract the indicators from the results of Mr. Pazuki's activities. The final model is presented and approved by both authors.

\section{ACKNOWLEDGMENT}

We would like to express our special thanks of gratitude to Ms. Mitra Ataei \& Mr. Kassra Miremadi who gave us the golden opportunity to do this research. We thank Ms. Nastaran Moossavi and Mr. Seyed Babak Moosavi Nejad for their advice which provided insight and expertise that greatly assisted the research. 
We thank Iranian Rural Communities for assistance with their time and knowledge, and Mr. Mahyar Khademi Bami for comments that greatly improved the manuscript.

We are immensely grateful for their comments on an earlier version of the manuscript, although any errors are our own and should not tarnish the reputations of these esteemed persons.

\section{REFERENCES}

[1] R. Chambers, "The poor and the environment: whose reality counts?" Centre for Development Research, 1994.

[2] D. Rigby, D. Howlett, and P. Woodhouse, "A review of indicators of agricultural and rural livelihood sustainability," 2000.

[3] C. Ashley and D. Carney, "Sustainable livelihoods: Lessons from early experience," London: Department for International Development, vol. 7, no. 1,1999

[4] I. Scoones, "Sustainable rural livelihoods: a framework for analysis," 1998.

[5] R. Chambers and G. Conway, "Sustainable rural livelihoods: Practical concepts for the 21st century," Institute of Development Studies (UK), 1992.

[6] A. Bond, A. Morrison-Saunders, and J. Pope, "Sustainability assessment: The state of the art," Impact Assessment and Project Appraisal," vol. 30, no. 1, 2012, pp. 53-62, 2012.

[7] G. C. Gallopin, "Indicators and their use: Information for decision-making," Scope-Scientific Committee on Problems of the Environment International Council of Scientific Unions, vol. 58, pp. 13-27, 1997.

[8] J. Chen and M. B. Beck, "Towards designing sustainable urban wastewater infrastructures: A screening analysis," Water Science and Technology, vol. 35, no. 9, pp. 99-112, 1997.

[9] D. Brownhill and S. Rao, "A sustainability checklist for developments: A common framework for developers and local authorities," Building Research Establishment, 2002.

[10] L. Emerton and H. Mogaka, "Participatory environmental valuation: subsistence forest use around the Aberdares, Kenya," African Wildlife Foundation, Nairobi, Kenya, vol. 38, pp. 1219-1240, 1996.

[11] R. Davies and W. Smith, The Basic Necessities Survey: The Experience of Action aid Vietnam, London: Action Aid, 1998.

[12] D. Sanderson, "Household livelihood security in urban settlements," Urban Briefing Notes, vol. 1, 1999.

[13] W. Bayer and A. Waters-Bayer, "Participatory monitoring and evaluation (PM\&E) with pastoralists: A review of experiences and annotated bibliography," 2002.

[14] D. Maxwell et al., "The coping strategies index: A tool for rapidly measuring food security and the impact of food aid programs in emergencies," Nairobi: CARE Eastern and Central Africa Regional Management Unit and the World Food Programme Vulnerability Assessment and Mapping Unit, 2003.

[15] J. A. E. Cavanagh, B. Frame, and J. Lennox, "The sustainability assessment model (SAM): Measuring sustainable development performance," Australasian Journal of Environmental Management, vol. 13, no. 3, pp. 142-145, 2006.

[16] D. Giovannucci et al., "Seeking sustainability. COSA preliminary analysis of sustainability initiatives in the coffee sector. Committee on Sustainability Assessment (COSA)," International Institute for Sustainable Development (IISD), Winnipeg, Canada, 2008.

[17] T. Yigitcanlar and F. Dur, "Developing a sustainability assessment model: The sustainable infrastructure, land-use, environment and transport model," Sustainability, vol. 2, no. 1, pp. 321-340, 2010.

[18] J. Boulenouar, R. Schweitzer, and H. Lockwood, "Mapping sustainability assessment tools to support sustainable water and sanitation service delivery," IRC International Water and Sanitation Centre: The Hague, the Netherlands, 2013.

[19] F. E. Milasi and B. Mahmoud, "Evaluation and prioritize of rura sustainable livelihoods indicators and criteria in Iran by the Delphi method," Rural Development Strategies, vol. 5, no. 2, 2018.
[20] M. Nourozi and D. Hayati, "Factors affecting sustainable rural livelihoods as perceived by farmers in Kermanshah province," Iranian Agricultural Extension and Education Journal, vol. 11, no. 1, 2015.

[21] E. Shakourifard et al., "Measuring the livelihood properties in rural areas using a sustainable livelihood approach (Case study: Rural areas of Taybad county)," Journal of Research and Rural Planning, vol. 5, no. 1, pp. 197-215, 2016.

Copyright $\odot 2020$ by the authors. This is an open access article distributed under the Creative Commons Attribution License which permits unrestricted use, distribution, and reproduction in any medium, provided the original work is properly cited (CC BY 4.0).

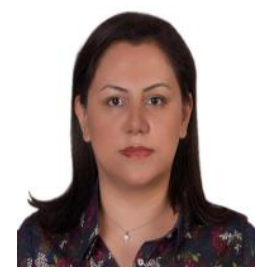

Leyla Khademibami was born in Iran, Tehran on September 21, 1979. She got the B.A. in industrial design, Tehran University, Tehran, Iran, 2004. She experienced in sustainable rural livelihoods.

She has over 15 years of work experience. In the past 8 years, she has been conducting a social business on creating sustainable and alternative livelihoods with the aim of reducing the pressure on natural resources. She also has participated in large scale projects under the United Nation Development Program and Small Grants Programs of Global Environmental Facilities, as a consoler, researcher and facilitator. She also wrote a book depend on her lessons learned with the title of "Livelihood and sustainable management of natural resources; a review of some applied model" sponsored by UNDP/GEF-FRWO joint project, MENARID. (Tehran, Omran, 2018).

Ms. Leyla Khademibami is a senior researcher in the Iranian Culture \& Sustainable Development Institute (ICSD). Also, she is research fellow \& member at SEERIO, Sharif University E-Commerce \& E-Government Research \& Innovation Organization, SME Development group.

During these years she has been working to improve the well-being of rural women and to provide them with sustainable livelihoods in various parts of Iran.

She has been acclaimed because of effective and innovative activities in the field of entrepreneurship and Sustainable livelihood by Vice President of Rural Development at the National Conference on Villages \& Nomads, and by DOE at the 2nd national conference on the Zagros's risks in her country, Iran.

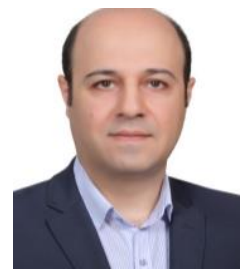

Pejman Pazouki was born in Iran, Tehran on September 12, 1977. He is M.Sc. student of rural development, Tehran University, Tehran, Iran.

With 18 years of experience in working with governmental organizations, international agencies, programs and NGOs as a project manager, Researcher and Facilitator, also Voluntary activities in the field of Environment \& Natural Resources Conservation, and as an active participant in the field of Livelihood and sustainable development, he is a well-known specialist on sustainable development in Iran.

$\mathrm{He}$ is also collaborating with most of the Developmental International Projects in Iran in the field of sustainable development as a planner, trainer \& facilitator. As a mentor and facilitator in the field of sustainable rural livelihood, he has experienced in collaboration with 70 rural and nomadic groups of local communities on the issues of improving to sustainable livelihoods.

He with Ms. Khademibami wrote the book with the title of "Livelihood and sustainable management of natural resources; a review of some applied model" sponsored by the UNDP/GEF-FRWO joint project, MENARID. (Tehran, Omran, 2018)

$\mathrm{He}$ also has been acclaimed by Vice President of Rural Development at the National Conference on Villages \& Nomads, and by DOE at the 2nd national conference on the Zagros's risks because of his effective efforts.

$\mathrm{He}$ is managing director of the Iranian Culture \& Sustainable Development Institute in Iran. 